\title{
Effect of Pterocarpus erinaceus Stem Bark Extracts on Haematological Parameters in Malaria Induced Anaemic Mice
}

\author{
Ibrahim Mohammed, Hauwa'u Shuaibu Mohammed, Modibbo Abdullahi Abubakar \\ Chemical Science Technology Department, Federal Polytechnic, Mubi, Nigeria \\ Email address: \\ ibrahimdodopg7019@gmail.com (I. Mohammed)

\section{To cite this article:} \\ Ibrahim Mohammed, Hauwa'u Shuaibu Mohammed, Modibbo Abdullahi Abubakar. Effect of Pterocarpus erinaceus Stem Bark Extracts on \\ Haematological Parameters in Malaria Induced Anaemic Mice. American Journal of Chemical and Biochemical Engineering. \\ Vol. 5, No. 1, 2021, pp. 21-25. doi: 10.11648/j.ajcbe.20210501.13
}

Received: February 24, 2021; Accepted: March 13, 2021; Published: April 16, 2021

\begin{abstract}
Traditionally Pterocarpus erinaceus stem bark have being widely used in treatment of anemia. The goal of this examination is to explore the viability of Pterocarpus erinaceus stem bark removes on jungle fever initiated paleness. Anaemia was induced by inoculation of $2 \mathrm{ml}$ of infected blood containing $0.1 \times 10^{7}$ Plasmodium beghei. The sickly mice were treated with 250 and $500 \mathrm{mg} /$ body weight of watery and ethanolic concentrates of Pterocarpus erinaceus stem bark for four days. The results shows that there is significant $(\mathrm{P}>0.005)$ increase in both haematological parameters ( $\mathrm{PCV}, \mathrm{Hb}$ and $\mathrm{RBC})$, haematological indices ( $\mathrm{MCV}, \mathrm{MCH}$ and $\mathrm{MCHC}$ ) and immunological parameters (WBC, platelets, neutrophils and lymphocytes) in malaria control compared to normal. Oral administration of 250 and $500 \mathrm{mg} / \mathrm{kg}$ body weight of aqueous and ethanolic extract of Pterocarpus erinaceus stem bark shows significant increase $(\mathrm{p}>0.05)$ in haematological parameters compared to malaria control. There were significant improvement in WBC, platelets, neutrophils, hympolytes and $\mathrm{MCH}$. Compared to malaria control. The anaemic mice treated with $250 / 500 \mathrm{mg} / \mathrm{kg}$ body weight of ethanolic extract showed significant improvement in both haematological and immunological parameters tested. These result suggest that Pterocarpus erinaceus stem bark can he used in managing anemia.
\end{abstract}

Keywords: Pterocarpus erinaceus, Anaemia, Malaria

\section{Introduction ${ }^{1}$}

Malaria is endemic in Nigeria with about $97 \%$ of the population at risk of infection sparing Sahel regions and high mountainous area of the Plateau. Currently, it represent almost 110 million clinically analyzed cases for each annum, $60 \%$ of outpatient visits and $30 \%$ hospitalization. It causes up to $11 \%$ maternal mortality, $25 \%$ baby mortality and $30 \%$ mortality in offspring of under five years [1].

Human, malaria is caused by a parasite in blood called plasmodia, five species of plasmodium genus can affect and transmit to humans, one of which is Plasmodium falciparum. The infected Female anopheles mosquitoes transmit the protozoa through a single bite of human [2].

\footnotetext{
${ }^{1}$ Acknowledgements: We truly which to appreciation Tertiary Education Trus Fund (TetFUND) Nigeria for supporting this research work.
}

Malaria contribute to the rise in anaemia cases causing morbidity and mortality in under 5 years children and pregnant women. The reduction in haemoglobin concentration is one mechanism of causing anaemia resulting in reduction of oxygen supply to other parts of the body from the heart. Plasmodium falciparum causes lysis of red blood cells or suppresses its production from bone marrow resulting in malarial anaemia [3].

In Africa, anaemia causes 5.64 million deaths of under five year children annually. Anaemia cases are often treated with one or more parts of plants [4]. Management of the disease using alternative medicine has been challenging. However, Phytochemicals and herbal products have proved effective in anaemic mice [5].

Traditional medicine has been in use in all malaria endemic countries for the treatment of the disease. Also, the use of Plasmodium falciparum drug resistant strain to 
antimalarial drugs are in the rise which pose a great challenge to the effort to control malaria globally. WHO [6] reported that there is increase in challenges from increase in cost of anti-malarial drugs, drug resistance of the Plasmodium falciparum to lack of effective vaccine; this has frustrated the global efforts to control malaria.

The aim of this study is to determine the effect of Pterocarpus erinaceus stem bark extracts on hematological parameters on malaria induced anaemia.

\section{Materials and Methods}

\subsection{Materials}

\subsubsection{Animals}

Mice (18-22g) of both sexes obtained from Animal Facility Centre, National Veterinary Research Institute Vom Jos, Nigeria were used for the study. The mice were kept in cages, diet and water were given at ad libitum. Laboratory conditions were maintained with light and dark cycle of 12 hours respectively. The Institute of Laboratory Animals Research (ILAR) Commission guide of 1996 on care and used of animal was followed.

\subsubsection{Plant Materials}

Pterocarpus erinaceus stem bark was collected at Vakna village in Maiha Local Government Area of Adamawa State, Nigeria. The identification taxonomically and authentication was carried out at Plant Science Department of Modibbo Adama University of Technology, Yola.

\subsubsection{Malaria Parasite}

Plasmodium berghei was obtained from National Institute of Medical Research, Yaba Nigeria.

\subsection{Methods}

\subsubsection{Extract Preparation}

Shade dried Pterocarpus erinaceus stem bark was reduced to powder using pestle and mortar. The powder weighing $160 \mathrm{~g}$ Pterocarpus erinaceus stem bark was macerated into $1000 \mathrm{~mL}$ of absolute ethanol for 24 hours with instantaneous shaking. The mixture was filtered using whatman no 1 filter paper.

To the aqueous extract, Pterocarpus erinaceus stem bark weighing $160 \mathrm{~g}$ was also macerated into $1000 \mathrm{~mL}$ of water with constant shaking for 24 hours, the mixture was filtered using whatman no 1 filter paper.

The filterate of both ethanolic and aqueous were concentrated to semi solid on water bath at $40^{\circ} \mathrm{C}$ and kept in desiccator. When extract is needed certain quantity will be measured and dissolved in distilled water for known contration.

\subsubsection{Parasite Inoculation}

This was carried out by determining both percentage parasitaemia and erythrocytes count of the donor mouse and diluting $0.2 \mathrm{ml}$ of infected erythrocytes with plasmodium berghei from donor mice with $3.0 \mathrm{ml}$ of phosphate buffer saline to give standard inoculums of $0.1 \times 10^{7}$. Each mouse was inoculated intraperitoneally on day one (1) with $0.2 \mathrm{ml}$ of infected blood containing $0.1 \times 10^{7}$ P. beghei parasitized red blood cells as described by Ryley and Peter [7]. After seventy two hours mice were treated for anaemic condition for four days once daily.

\subsubsection{Experimental Design for Malaria Induced Anaemia}

Forty two mice of male sex weighing $22.5 \mathrm{~g}$ were utilized in this investigation. The mice were haphazardly isolated into six groups of seven mice for every group. Each group were taken care of and treated as follows:

Group 1. Served as normal. They received neither inoculated with the parasites nor extracts. They received only normal feeds.

Group 2. Served malaria control. They were inoculated with $0.2 \mathrm{ml}$ of $1 \times 10^{7}$ infected erythrocytes containing plasmodium berghei and given normal feed.

Group 3. They were inoculated with $0.2 \mathrm{ml}$ of $1.0 \times 10^{7}$ infected erythrocytes containing plasmodium berghei and administration of $250 \mathrm{mg} / \mathrm{kg}$ body weight of aqueous extract of pterocarcus erinaceus stem bark begins on the fourth day for four days.

Group 4. They were inoculated with $0.2 \mathrm{ml}$ of $1.0 \times 10^{7}$ infected erythrocytes containing plasmodium berghei and administration of $500 \mathrm{mg} / \mathrm{kg}$ body weight of aqueous extract of pterocarcus erinaceus stem bark begins on the fourth day for four days.

Group 5. They were inoculated with $0.2 \mathrm{ml}$ of $1.0 \times 10^{7}$ infected erythrocytes containing plasmodium berghei and administration of $250 \mathrm{mg} / \mathrm{kg}$ body weight of ethanolic extract of pterocarcus erinaceus stem bark begins on the fourth day for four days.

Group 6. They were inoculated with $0.2 \mathrm{ml}$ of $1.0 \times 10^{7}$ infected erythrocytes containing plasmodium berghei and administration of $500 \mathrm{mg} / \mathrm{kg}$ body weight of ethanolic extract of pterocarcus erinaceus stem bark begins on the fourth day for four days.

Twenty four hours after administration of the concentrates, the mice were penance and blood tests were collected utilizing heart cut. The blood tests were placed into EDTA compartment and permitted to represent 30 minutes to clump and rotator at $2500 \mathrm{rpm}$ for 10 minutes and serum was gathered for biochemical investigation.

\subsection{Determination of Haematological and Some Biochemical Parameters}

\subsubsection{Packed cell Volume (Hematocrit Method)}

The pack cell volume (PCV) was resolved to foresee the adequacy of the ethanolic extricate. Blood was drawn from the tail of the mice in the various gatherings. Three-fold conclusions of the hematocrit stuffed cell volume were done to decide the general volume of blood involved by erythrocytes.

Procedure:

Blood was straightforwardly taken from the tail of the mice into heparinized hairlike cylinder to around three-fourth of the length. One top of the cylinder was totally fixed utilizing plastacine wax. The fixed slim cylinder was moved to hematocrit axis put in such a way that the fixed end point 
outward. The front of the axis was fixed to forestall blood spillage and centrifuged at 1,500 rpm for 5 minutes.

From that point, the slender cylinders are moved to the graphite peruser and the rate pressed cell volume read straightforwardly.

$$
\text { Packed cell volume }=\frac{\text { volume of erythrocyte in a given volume of blood }}{\text { Total blood volume }}
$$

\subsubsection{Haemaglobin Determination (Cynmethaemoglobin Method)}

Procedure:

Blood $(0.02 \mathrm{~mL})$ was added to $5 \mathrm{~mL}$ of Drabkin's solution in a test tube. Mixed well and allowed to stand for 10 minutes. Absorbance was read at 540nm against Drabkin's solution as blank.

$$
\text { Hb conc. }\left(\frac{\mathrm{g}}{100 \mathrm{ml}}\right)=\frac{\text { Reading test }}{\text { Reading of standard }} \times \frac{\text { concentration of standard }}{4}
$$

\subsubsection{Red Cell Count (Manual Method)}

The blood $(0.2 \mathrm{~mL})$ was weakened with $3.98 \mathrm{~mL}$ of weakening liquid. The all out number of red cells was included in five gatherings of 16 little squares in the focal governed territory which is equivalent to $80 / 400 \mathrm{~mm}$ i.e. $0.2 \mathrm{~mm}^{2}$ under microscope.

Total indices was count/cu.mm=Number of cell counted $\mathrm{x}$ 10,000

Blood indices was also calculated as describe by Baker et al., [8].

$$
\begin{aligned}
& M C V(f l)=\frac{P C V}{R B C} \\
& \mathrm{MCH}(\mathrm{pg})=\frac{H b \times 10}{R B C} \\
& M C H C \frac{g}{d L}=\frac{H b}{P C V}
\end{aligned}
$$

\subsubsection{White Blood Count (Leishman's Stain Method)}

Procedure:

a. Thin blood films were prepared and fixed in leishman's stain for 1-2 minutes

b. Equal volume of phosphate buffer solution ( $\mathrm{pH}$ 6.8) was added and mixed.

c. The slide was washed and differentiated with phosphate buffer solution ( $\mathrm{pH}$ 6.8), the smear appeared salmonpink colour.

d. The slide was drained and air dried at room temperature. Back of slide was cleaned and examined under microscope at $100 \times$ lens.

Result

Orange-red Eosinophils

Dark blue Basophile

Dark blue Lymphocytes

Violet red Platelets

Statistical Analysis

The mean and standard error of mean (SEM) were calculated for each parameter carried out. The results were statistically analyzed using student's t-test. The difference between the means where considered significant at $p$ value less than five percent $(\mathrm{p} \leq 0.05)$.

\section{Result and Discussion}

\subsection{Result}

Table 1. Effect of Pterocarpus erinaceus stem bark on haematological parameters in malaria-induced anaemia.

\begin{tabular}{llll}
\hline Treatment & RBC X $\mathbf{~ 1 0}^{\mathbf{6}}\left(\boldsymbol{\mu}^{-1}\right)$ & Hb (G/dl) & PCV (\%) \\
\hline Normal & $7.53 \pm 0.23$ & $11.39 \pm 0.38$ & $38.71 \pm 2.51$ \\
Malaria control & $2.72 \pm 0.31$ & $6.60 \pm 0.70$ & $22.34 \pm 2.95$ \\
Anaemia $+250 \mathrm{mg} / \mathrm{kg}$ bw E. E & $5.99 \pm 0.33^{*}$ & $8.34 \pm 0.58$ & $30.57 \pm 2.10^{*}$ \\
Anaemia $+250 \mathrm{mg} / \mathrm{kg}$ bw A. E & $5.65 \pm 0.43^{*}$ & $8.16 \pm 1.09$ & $33.36 \pm 1.04^{*}$ \\
Anaemia $+500 \mathrm{mg} / \mathrm{kg}$ bw E. E & $6.25 \pm 0.29^{*}$ & $9.37 \pm 0.91^{*}$ & $37.39 \pm 2.23^{*}$ \\
Anaemia $+500 \mathrm{mg} / \mathrm{kg}$ bw A. E & $6.66 \pm 0.24^{*}$ & $10.90 \pm 0.38^{*}$ & $57.47 \pm 0.77^{*}$ \\
\hline
\end{tabular}

Value are mean \pm SEM, $\mathrm{n}=7$

${ }^{*}$ Significantly different when compared to malaria control group $(\mathrm{P} \leq 0.05)$

E. E=Ethanolic Extract, A. E=Aqueous Extract, RBC (Red Blood Count), Hb (Haemoglobin)

PCV (Pack Cell Volume)

\subsection{Discussion}

Red blood cells deliver oxygen from lungs to other part of the body and take carbon dioxide back to lungs. The movement of this gas occurs with the help of haemoglobin which is a tetramer protein containing haeme and globin protein. Decrease in exchange of gases (oxygen and carbon dioxide) as a result of decrease in red blood cells (RBC) 
result in the condition called anaemia [9]. Iron deficiency is a component of intestinal sickness and regular among everybody in jungle districts, especially Africa and most particularly in kids and pregnant ladies [10].

Table 2. Effect of Pterocarpus erinaceus stem bark on haematological parameters in malaria-induced anaemia.

\begin{tabular}{llll}
\hline Treatment & MCV (fil) & MCH (Pg) & MCHC (g/dl) \\
\hline Normal & $51.67 \pm 2.51$ & $15.16 \pm 0.46$ & $29.54 \pm 1.20$ \\
Malaria control & $49.10 \pm 11.25$ & $23.83 \pm 2.64$ & $31.84 \pm 4.13$ \\
Anaemia $+250 \mathrm{mg} / \mathrm{kg}$ bw E. E & $51.79 \pm 4.00$ & $14.16 \pm 1.18^{*}$ & $27.26 \pm 0.34$ \\
Anaemia $+250 \mathrm{mg} / \mathrm{kg}$ bw A. E & $68.60 \pm 8.24$ & $14.41 \pm 1.70^{*}$ & $24.69 \pm 0.35$ \\
Anaemia $+500 \mathrm{mg} / \mathrm{kg}$ bw E. E & $76.21 \pm 5.68$ & $15.47 \pm 1.62^{*}$ & $25.31 \pm 2.11$ \\
Anaemia $+500 \mathrm{mg} / \mathrm{kg}$ bw A. E & $57.47 \pm 2.31$ & $16.69 \pm 0.39^{*}$ & $30.24 \pm 0.50$ \\
\hline
\end{tabular}

Value are mean \pm SEM, $n=7$

${ }^{*}$ Significantly different when compared to malaria control group $(\mathrm{P} \leq 0.05)$

MCV (Mean Cell Volume), MCH (Mean Cell haemoglobin), MCHC (Mean Cell Haemoglobin Concentration)

Table 3. Effect of Pterocarpus erinaceus stem bark on immunological parameters in malaria-induced anaemia.

\begin{tabular}{|c|c|c|c|c|}
\hline Treatment & WBC $\times 10^{3} \times(\mu \mathrm{l})$ & Platelet $\times 10^{3}\left(\mu \mathrm{I}^{-1}\right)$ & Neutrophils (\%) & Lymohocyte (\%) \\
\hline Normal & $6.59 \pm 0.15$ & $1116 \pm 102.02$ & $34.50 \pm 8.33$ & $66.00 \pm 8.33$ \\
\hline Malaria control & $24.79 \pm 2.14$ & $275.86 \pm 22.62$ & $18.14 \pm 0.34$ & $81.85 \pm 0.34$ \\
\hline Anaemia $+250 \mathrm{mg} / \mathrm{kg}$ bw E. E & $15.73 \pm 1.17^{*}$ & $538.29 \pm 12.19^{*}$ & $23.57 \pm 1.86^{*}$ & $76.71 \pm 1.87^{*}$ \\
\hline Anaemia $+250 \mathrm{mg} / \mathrm{kg}$ bw A. E & $5.09 \pm 0.20^{*}$ & $764.28 \pm 59.40^{*}$ & $17.71 \pm 3.06$ & $82.29 \pm 3.06$ \\
\hline Anaemia $+500 \mathrm{mg} / \mathrm{kg}$ bw E. E & $15.29 \pm 1.87^{*}$ & $752.86 \pm 58.33^{*}$ & $27.57 \pm 3.05^{*}$ & $72.43 \pm 3.05^{*}$ \\
\hline Anaemia $+500 \mathrm{mg} / \mathrm{kg}$ bw A. E & $4.11 \pm 0.59^{*}$ & $824.43 \pm 50.17^{*}$ & $20.57 \pm 1.36$ & $69.43 \pm 3.90^{*}$ \\
\hline
\end{tabular}

Value are mean \pm SEM, $n=7$

${ }^{*}$ Significantly different when compared to malaria control group $(\mathrm{P} \leq 0.05)$

E. E=Ethanolic Extract, A. E.=Aqueous Extract, WBC (White Blood Count)

Nadro and Modibbo [11] reported that the toxicity level of aqueous stem bark extract of Pterocarpus erinaceus is higher than $5,000 \mathrm{mg} / \mathrm{kg}$ Body weight. The dose used in this study 250 and $500 \mathrm{mg} / \mathrm{kg}$ body weight is safer.

Reasonable way to deal with jungle fever is fundamental if the worldwide targets of intestinal sickness control are to be accomplished. The haematological indices such as $\mathrm{Hb}, \mathrm{PCV}$, and RBC have been set up that the level of iron deficiency consistently relates with increment in parasitemia and level of PCV [12]. There was a significant reduction $(p<0.05)$ in the values of PCV and RBC after inoculating with malaria parasites when compared to normal group. Anaemic mice treated with aqueous and ethanolic extracts at 250 and $500 \mathrm{mg} / \mathrm{kg}$ body weight shows significant increase in the PCV, $\mathrm{Hb}$ and RBC values compared to infected control. Increase in the haematological indices indicates that the extracts may have the capacity to successfully hinder the development of the parasite in the red platelets (Table 1).

The constituents of fluid and ethanolic concentrate of Pterocarpus erinaceus stem bark may have stimulatory impact on the bone marrow for erythrocytes amalgamation. This observed effect may be as a result of the presence of tannins, ascorbic acid, folic acid, vitamin $\mathrm{B}_{12}$ and phenolic compounds [13]. Other chemical constituents of Pterocarpus erinaceus stem bark which may likely affect haematological parameters includes flavonoids (antioxidant and free radical scavenger), zinc, riboflavin, niacin [14]. Maryam et al., [15] reported that Pterocarpus erinaceus stem bark have high concentration of iron, copper, phosphorus, vitamin $\mathrm{B}_{9}$ and vitamin $\mathrm{A}$ and low in other minerals and vitamins. Red Blood Cell (RBC) is related to $\mathrm{MCV}, \mathrm{MCHC}$ and $\mathrm{MCH}$ while the total population of RBC is associated with PCV and $\mathrm{Hb}$ [16]. The observed increase in MCV, MCHC and $\mathrm{MCH}$ as shown in table 2 suggested that Pterocarpus erinaceus stem bark extracts stimulate erythropoietin hormone release in the kidney for RBC production [17].

WBC, lymphocytes and neutrophils are immunological indices of the body against infections. Any substance that affect the body may lead to immunological incapacitations. There were critical expansion in WBC, lymphocytes and there is significantly decrease in neutrophils and platelets due to the presence of microbial infection (Plasmodium berghei) induced anaemia. Administration of the extracts significantly improved the parameters tested.

\section{Conclusion}

The ethanolic and aqueous extracts Pterocarpus erinaceus stem bark have increase the blood and defensive mechanism of the body against malaria. Therefore, the extracts have anti anaemic properties.

\section{References}

[1] Strategic plan (2009). A Road Map for Malaria Control in Nigeria. Federal Ministry of Health, National Malaria Programme, Abuja Nigeria. 1-3.

[2] Umar, T. T., Umar, I. A and Ibrahim, A. (2007), phytochemical analysis and in vitro ant plasmodium activity of Chrozophora senegalensis extract on Plasmodium falciparum. Nig. Journal of chemical research. Vol. 22 (2): 62-71. 
[3] Sumbele, I. U. N., Sama S. O., Kimbi, H. K. and Taiwe G. S. (2016). Malaria, Moderate to Severe Anaemia, and Malarial Anaemia in Children at Presentation to Hospital in the Mount Cameroon Area: A Cross-Sectional Study. Anemia Volume 2016, Article ID 5725634, 12 pages.

[4] Suzanne, B. B. S., Adeline, F. Y. S., Theodora, K. K., Dairou, H., Pradel, K. L., Aristide, K. M., Mathieu, N., Gabriel, A. A., Anne, N. N. R. and Clerge, T. (2020). Hemopoietic effects of some herbal extracts used in treatment of infantile anemia in Cameroon. WJPMR, 6 (1), 147-155.

[5] Anjusha, K. V., Mamun, M. A. A., Dharmakar, P. and Shamima, N. (2019). Effect of Medicinal Herbs on Hematology of Fishes. Int. J. Curr. Microbiol. App. Sci 8 (9): 2371-2376.

[6] WHO (2010). In vivo micro-test (Mark -111) for the assessment of the response of plasmodium falciparum to chloroquine, mefloquine, quinine, amodaquine, sulfodoxine/pyrimethamin and artemisinin, instruction for use of the in vitro micro-test kit (mark 111) $2001 \mathrm{ciD} / \mathrm{mal} / 97.20$ Rev. 2.

[7] Ryley, J. F. and Peters, W. (1970). The antimalarial activity of some quinolone esters. Ann. Trop. Med. Parasitol. 84: 209222.

[8] Baker, F. J., Silverton, R. E. and Pallister, C. J. (1998). Baker and Silverston's: Introduction to Medical Laboratory Technology. $7^{\text {th }}$ Edition. Bounty Press LTD. London 337-338.

[9] Veng-paderson, P., Chapel, S., Schmidt, R. L., Al-Huniti, N. H., Cook, R. T and Widness J. A. (2002), An integrated pharmacodynamics analysis of erythropoietin, reticulocyte, and haemoglobin responses in acute anaemia. Pharm Res. 19 (11): $1630-5$.

[10] Beales P. E (1997), Anaemia in malaria control: a practical approach Ann Trop Med. Parasitol. 91: 713-18.

[11] Nadro, M. S. and Modibbo, A. A. (2014). Effect of Pterocarpus erinaceus stem bark aqueous extract on anemic rats. SCIR II (V): 1-5.

[12] Iwalewa E. O, (1995). Evaluation of anti-malerial properties of Cassia occidentalis' and Azadiracha indica' leaves. Published PhD thesis Ahmadu Bello University, Zaria, Nigeria.

[13] Okwu, D. E. (2004). Phytochemical and vitamin content of indigenous spices of South Eastern Nigeria. J. Sustain. Agric. Environ. 6: 30-34.

[14] Salahdeen, H. M and Yemitan. K (2006). Neuropharmacologic effects of aqueous leaf extract of Brayophyllum pinnatum Afr. J. Biomed. Res. 9: 101-107.

[15] mMaryam, M. U., Abdullahi, A. M., Moses, Z. Z. and Ismaila, Y. S. (2017). Phytochemical and Nutrient composition of Pterocarpus erinaceus stem bark. Inter. J. of Biochemi. Res. And Rev. 1-6.

[16] Mishra, n. and Tandon, V. L. (2012). Haematological effect of aqueous extract of Ornamental plants in Male Swiss albino rats. Vet. World. 5 (1): 19-23.

[17] Jorum, O. H., Piero, N. M. and Machocho, A. K. (2016). Haematological effects of dichloromethane-methanolic leaf extracts of Carissa edulis (Forssk) vahl in normal rats' models. J. of Haem. And Thromboembolic Disease. 4: 232-236. 